https://helda.helsinki.fi

\title{
Excess Body Mass and Leisure Time Physical Activity in the Incidence and Persistence of Chronic Pain
}

\section{Shiri, Rahman}

2020-11

Shiri , R , Lallukka , T , Rahkonen , O \& Leino-Arjas , P 2020 , ' Excess Body Mass and Leisure Time Physical Activity in the Incidence and Persistence of Chronic Pain ' , Pain Medicine , vol. 21 , no. 11 , pp. 3094-3101 . https://doi.org/10.1093/pm/pnaa102

http://hdl.handle.net/10138/337600

https://doi.org/10.1093/pm/pnaa102

unspecified

acceptedVersion

Downloaded from Helda, University of Helsinki institutional repository.

This is an electronic reprint of the original article.

This reprint may differ from the original in pagination and typographic detail.

Please cite the original version. 
Excess body mass and leisure-time physical activity in the incidence and persistence of chronic pain

Rahman Shiri, MD, PhD, ${ }^{1}$ Tea Lallukka, PhD,${ }^{1,2}$ Ossi Rahkonen, $\mathrm{PhD},{ }^{2}$ Päivi Leino-Arjas, $\mathrm{MD}, \mathrm{PhD}^{1}$

${ }^{1}$ Finnish Institute of Occupational Health, Helsinki, Finland

${ }^{2}$ Department of Public Health, University of Helsinki, Helsinki, Finland

Abstract word count: 240

Text word count: 2600

Number of tables: 4

Number of figures: 1

Correspondence to:

Rahman Shiri

Finnish Institute of Occupational Health

P.O. Box 18

FI-00032 Työterveyslaitos, Helsinki

Email:rahman.shiri@ttl.fi 


\section{Funding source}

The Finnish Work Environment Fund (grant no:117141) and the Academy of Finland (grant no: $1294514 \& 287488 \& 319200)$ supported this study.

\section{Declaration of interest}

The authors declare that they have no conflicts of interest.

Running title: Excess body mass in chronic pain

\section{Contributors' Statement}

TL and OR participated in design and acquisition of the data. RS carried out the analyses. All authors interpreted the results and participated in the preparation of the manuscript. All authors reviewed the final version of the manuscript and approved it to be submitted for publication. 


\begin{abstract}
OBJECTIVE: To estimate the effects of excess body mass and leisure-time physical activity on the incidence and persistence of chronic pain.
\end{abstract}

DESIGN: A prospective cohort study.

METHODS: As a part of the Finnish Helsinki Health Study, we included three cohorts of employees of the City of Helsinki (18562 observations) and defined incident chronic pain as having pain in any part of the body $>3$ months at follow-up in participants without chronic pain at baseline ( $\mathrm{N}=13029$ observations). Persistent chronic pain was defined as having pain >3 months at both baseline and follow-up ( $\mathrm{N}=5533$ observations).

RESULTS: Overweight (adjusted odds ratio $(\mathrm{OR})=1.18,95 \%$ CI 1.06-1.31) and obesity $(\mathrm{OR}=1.65, \mathrm{CI} 1.45-1.88)$ increased the incidence of chronic pain. Moreover, overweight $(\mathrm{OR}=1.16, \mathrm{CI} 1.02-1.32)$ and obesity $(\mathrm{OR}=1.48, \mathrm{CI} 1.26-1.74)$ increased the risk of persistent chronic pain. Vigorous leisure-time physical activity reduced the incidence of chronic pain $(\mathrm{OR}=0.85$, CI $0.75-0.96)$. Physical activity did not influence the risk of persistent chronic pain. Furthermore, overweight/obesity modified the effect of leisure-time physical activity on incident chronic pain. Inactive overweight or obese participants were at the highest risk of chronic pain $(\mathrm{OR}=1.71$, CI 1.40-2.09), while the OR dropped to 1.44 (CI 1.19-1.75) in moderately active overweight or obese participants and to 1.20 (CI 0.97-1.47) in highly active overweight or obese participants.

CONCLUSION: Obesity not only increases the risk of developing chronic pain, but also increases the risk of persistent pain, while leisure-time physical activity reduces the risk of developing chronic pain.

KEYWORDS: Exercise, leisure activities, overweight, obesity 


\section{Introduction}

Chronic pain is a common condition in the general population [1-6], and a common reason to visit a primary care doctor [7], a medical specialist [5] or other health professionals [5]. Chronic pain contributes to disability and mental health problems, reduces the quality of life and imposes high burden on society $[5,6,8,9]$. Previous studies estimate that $16 \%$ to $43 \%$ of the general population report pain in any body site lasting longer than three months [1-6]. Furthermore, the prevalence of chronic pain has increased over time [1, 2], is more common in women than in men, and increases with age [1-6]. The most common sources of chronic pain in adults are back disorders, arthritis and headache [6].

Many cross-sectional studies have found that chronic pain is more common in people who are overweight or obese than in individuals who are normal weight $[5,10-13]$. Both body mass index and abdominal obesity defined by waist circumference have shown similar relationships with chronic pain [14]. Obesity and chronic pain are comorbid conditions and have adverse effects on each other [15], and reverse causation cannot be ruled out in cross-sectional studies. Thus, overweight/obesity can be either a cause or a consequence of chronic pain. Prospective cohort studies on this topic are, however, scarce.

To date, the role of exercise and other leisure-time physical activities in chronic pain is still uncertain [16]. Systematic reviews of controlled trials showed that exercise reduces pain severity and improves physical functioning [16], however, the size of beneficial effects of exercise on pain is small [16]. Similarly, a systematic review and meta-analysis of observational studies [17] found that leisure-time physical activity reduces the risk of developing chronic low back pain only by $10-15 \%$. 
To date, little is known whether overweight or obesity modifies the effect of leisure-time physical activity on chronic pain. A population-based prospective cohort study [18] found that exercise compensates, to some degree, for the adverse effect of excess body mass on chronic musculoskeletal pain. The aim of the current study was to estimate the effects of body mass index and leisure-time physical activity on the incidence of chronic pain and risk of persistent chronic pain and to determine whether body mass index modifies the effect of leisure-time physical activity on these outcomes.

\section{Methods}

\section{Population}

This study is part of the ongoing Finnish Helsinki Health Study [19]. A total of 8960 employees of the City of Helsinki aged 40 to 60 years (response rate 67\%) participated in the baseline survey in 2000/2002 (Figure 1) and 8755 responded to pain questions. Of those, 7132 took part in the first follow-up survey in 2007, 6664 in the second in 2012, and 6518 in the third follow-up survey in 2017. Three cohorts (2000/2002-2007, 2007- 2012, and 2012-2017) were included in the current analysis. After excluding subjects with missing data, 7000 participants were included in the 2000/2002-2007 cohort, 5973 in the 2007- 2012 cohort, and 5589 in the 2012-2017 cohort. Altogether 13029 observations without chronic pain at baseline were included in the analyses on incident chronic pain, and 5533 observations with chronic pain at baseline in the analysis on persistent chronic pain.

The ethics committees of the health authorities of the City of Helsinki and of the Department of Public Health, University of Helsinki, approved the study. 


\section{Lifestyle factors (exposure variables)}

Leisure-time physical activity, including commuting, was assessed with four identical questions in all phases [20]. Information on the participants' average weekly hours of leisuretime physical activity within the past 12 months was collected regarding four grades of intensity: 1) walking, 2) brisk walking, 3) jogging, and 4) running, or their equivalent activities [21]. The number of hours per week for each activity grade ranged between 0 and 4 hours. A metabolic equivalent (MET) index was calculated for each participant by multiplying the MET-values of each activity intensity by the time spent on them, and summing [20, 21]. The intensity of leisure-time physical activity was classified into three groups: low (<14 METhours per week), moderate ( $\geq 14$ MET-hours of moderate intensity activities with no vigorous activities), and vigorous ( $\geq 14$ MET-hours, including some vigorous activity such as jogging or running) activity. The three groups were mutually exclusive. Body weight and height and tobacco smoking status were self-reported in all phases [20]. Body mass index (BMI) was calculated based on weight and height and grouped into four levels: underweight (BMI $<18.5$ $\mathrm{kg} / \mathrm{m}^{2}$ ), normal (BMI 18.5-24.9 kg/m²), overweight (BMI 25.0-29.9 kg/m²) and obese (BMI $\geq 30 \mathrm{~kg} / \mathrm{m}^{2}$ ). Smoking status was classified into never smokers, past smokers and current daily smokers of cigarettes, cigars or pipe.

\section{Chronic pain (outcome)}

Information on current pain was gathered by two identical questions in all phases. The first question was: "Do you have any pain or ache right now? (No/Yes)". Those who gave an affirmative response were further asked: "When did the pain start? (not more than 3 months ago/ more than 3 months ago)". The outcome variable in the current study was chronic pain, defined as pain or ache in any part of the body for longer than 3 months. We defined incident 
chronic pain as having pain for longer than 3 months at follow-up in participants free from chronic pain at baseline, and persistent chronic pain as having pain for longer than 3 months at both baseline and follow-up.

\section{Covariates}

Information on age, gender, marital status (single, cohabiting, married, divorced or widowed), education (elementary school, middle school, vocational school or equivalent, college degree, university degree), household income, and frequency of alcohol consumption was gathered in all surveys. Physical workload factors were assessed with eight items: (i) awkward postures, (ii) rotation of back, (iii) repetitive movements, (iv) standing, (v) sitting, (vi) walking, (vii) heavy physical effort or lifting and carrying heavy loads, and (viii) vibration. Job demands and job control were assessed using the Karasek's Job Content Questionnaire [22].

\section{Statistical analysis}

We used the generalized estimating equation method to analyze repeated measures data on chronic pain [23]. We adjusted the estimates for age (continuous), gender, education, marital status, household income, smoking, body mass index, leisure-time physical activity, job demands (continuous), job control (continuous), heavy physical work or lifting/carrying heavy loads, awkward posture, rotation of the back, repetitive movements, and prolonged standing or sitting. We performed gender-specific analyses and stratified analyses by body mass index to determine whether overweight or obesity modifies the effect of leisure-time physical activity on chronic pain. In the models, we tested for the presence of multiplicative interaction of body mass index (two groups: overweight or obesity vs. normal) with leisure-time physical activity (three groups). Furthermore, in the analysis of incident chronic pain we conducted a sensitivity analysis including only the participants free from any pain at baseline (acute/subacute or 
chronic pain). We used STATA, version 15, (StataCorp, College Station, TX, USA) for the analyses.

\section{Results}

\section{Incident chronic pain}

Of 13029 observations without chronic pain at baseline (Table 1), 34.7\% were overweight and $14.8 \%$ obese at baseline. Furthermore, $17.9 \%$ were current daily smokers, $38.5 \%$ were moderately and $40.0 \%$ highly active during leisure-time. Overall, $20.5 \%$ reported incident chronic pain at follow-up.

Obesity was associated with incident chronic pain in both men (odds ratio $(\mathrm{OR})=1.47,95 \%$ CI 1.06-2.04, Table 2) and women (OR =1.68, CI 1.46-1.94) after adjustment for age, education, smoking and leisure-time physical activity, whereas overweight was associated with incident chronic pain in women only $(\mathrm{OR}=1.21, \mathrm{CI} 1.08-1.36$, Table 2). Vigorous leisure-time physical activity was inversely associated with incident chronic pain in women only $(\mathrm{OR}=$ 0.84, CI 0.73-0.96) after adjustment for age, education, smoking and body mass index. Among those occupationally active and with information available on work-related factors $(\mathrm{N}=9383$ observations), both overweight $(\mathrm{OR}=1.13, \mathrm{CI} 1.00-1.27)$ and obesity $(\mathrm{OR}=1.54, \mathrm{CI} 1.32-1.79)$ were associated with incident chronic pain after adjustment for age, gender, education, marital status, household income, smoking, leisure-time physical activity, job demands, job control, heavy physical work or lifting/carrying heavy loads, awkward posture, rotation of the back, repetitive movements, prolonged standing and prolonged sitting (Table 3). Leisure-time physical activity was not associated with incident chronic pain. In gender-specific analyses, the OR for overweight was 0.96 (CI 0.72-1.28) in men and 1.16 (CI 1.02-1.32) in women and the 
OR for obesity was 1.38 (CI 0.93-2.04) in men and 1.56 (CI 1.32-1.84) in women. Leisuretime physical activity was not associated with chronic pain in either men or women.

Overweight or obesity modified the effect of leisure-time physical activity on incident chronic pain (Table 4). Leisure-time physical activity compensated for the adverse effect of overweight or obesity on incident chronic pain. There was a statistically significant multiplicative interaction between overweight/obesity and moderate $(\mathrm{P}$ for interaction $=0.01)$ and vigorous $(\mathrm{P}$ for interaction $=0.002$ ) leisure-time physical activity for incident chronic pain. Overweight or obese participants who were also inactive during leisure time were at the highest risk of chronic pain $(\mathrm{OR}=1.71$, CI 1.40-2.09), while the OR dropped to 1.44 (CI 1.19-1.75) in overweight or obese participants who were moderately active and to 1.20 (CI 0.97-1.47) in overweight or obese participants who were highly active (Table 4). In a sensitivity analysis, where we included only participants free from acute/subacute or chronic pain at baseline (10260 observations), the results were similar to the main analysis of the 13029 observations without chronic pain at baseline.

\section{Persistent chronic pain}

Of the 5533 observations with chronic pain at baseline (Table 1), 37.8\% were overweight, $21.9 \%$ obese, and $18.6 \%$ were current daily smokers. Moreover, $42.2 \%$ were moderately and 29.7\% highly active during leisure-time. At follow-up, 55\% experienced persistent chronic pain.

After adjustment for age, education, smoking and leisure-time physical activity, overweight $(\mathrm{OR}=1.19, \mathrm{CI} 1.04-1.37)$ and obesity $(\mathrm{OR}=1.52, \mathrm{CI} 1.28-1.81)$ increased the risk of persistent chronic pain in women only. Moderate and high levels of leisure-time physical activity reduced the risk in men; however, the estimates did not reach statistical significance 
after adjustment for age, education, smoking and body mass index (Table 2). Among the occupationally active with data available on work-related factors (3792 observations), only obesity increased the risk of persistent chronic pain in both genders combined $(\mathrm{OR}=1.30, \mathrm{CI}$ 1.08-1.58, Table 3). In gender-specific analyses, the OR for obesity was 1.26 (CI 1.02-1.54) in women and 1.64 (CI 0.97-2.78) in men, while it was 0.61 (CI 0.39-0.96) for moderate and 0.74 (CI 0.48-1.13) for high leisure-time physical activity in men.

Overweight or obesity did not modify the effect of leisure-time physical activity on persistent chronic pain (Table 4).

\section{Discussion}

The current prospective cohort study among municipal employees suggests that being overweight or obese increases the risk of incident as well as persistent chronic pain. Vigorous leisure-time physical activity reduced the risk of new episodes of chronic pain, but not that of persistent chronic pain.

\section{Association between BMI and chronic pain}

Most of the previous studies on the associations of excess body mass and leisure-time physical activity with chronic pain have been cross-sectional. Because of physical disability or fear of movement, individuals with chronic pain are more likely to be physically inactive than individuals without chronic pain [24]. Physical inactivity consequently leads to weight gain and overweight [25]. In line with our results on any chronic pain, a large prospective cohort study showed that both overweight and obesity increased the risk of chronic musculoskeletal pain, whereas leisure-time physical activity reduced the risk [18]. Our results show that obesity 
not only increases the risk of new episodes of chronic pain, but also that of persistent pain. Also among young people, obese individuals showed smaller improvement in chronic pain over time than normal weight individuals [26].

To date, very few studies have determined whether overweight or obesity modifies the effect of leisure-time physical activity on chronic pain. The present study suggests that both moderate and high levels of physical activity during leisure-time protect against the development of chronic pain in overweight or obese individuals. In line with the current study, prospective cohort studies found that leisure-time physical activity compensates to some extent for the adverse effect of overweight/obesity on chronic pain [18] and low back pain [27].

In gender-specific analysis, overweight slightly increased the risk of incident and persistent chronic pain in women only. A stronger effect of excess body mass on musculoskeletal pain in women than men has also been reported by other studies [28, 29]. In the present study, the effect of obesity on persistent chronic pain was not statistically significant in men, which is more likely due to low statistical power of the study. Vigorous leisure-time physical activity reduced the risk of persistent chronic pain in men only. Of the participants with persistent chronic pain, men were more active during leisure-time than women (48\% vs. 39\%), however, the observed difference may be due to a relatively small male population.

\section{Mechanisms}

Mechanisms underlying the association between obesity and chronic pain are not well-known. The effect of obesity on chronic pain may be mediated through mechanical loading, inflammation, and psychological factors [30]. Obesity can cause pain via abdominal loading on weight-bearing joints [31]. Reducing abdominal fat reduces the systemic markers of inflammation [32]. Leisure-time physical activity may therefore reduce chronic pain through 
reducing systemic inflammation in individuals who are obese [32]. However, a study [14] found that the association of abdominal obesity with chronic pain is independent of insulin resistance, inflammatory marker of high-sensitivity C-reactive protein, osteoarthritis, and neuropathy. The association between excess body mass and chronic pain can also partly be explained by depression [33].

Exercise may have modest beneficial effects on chronic pain [34]. However, it is still unclear what types of exercise are effective in the prevention and management of chronic pain [34]. In people free from chronic low back pain, moderate or vigorous leisure-time physical activity protects against the development of chronic low back pain [17], and in patients with chronic low back pain, walking reduces pain and disability [35]. Moreover, in patients with chronic pain, weight loss improves health-related quality of life [24]. Future studies should explore whether physical activity during leisure-time plus diet low in fat and sugar can prevent against chronic pain and whether moderate or vigorous leisure-time physical activity reduces the rate of recurrent or persistent chronic pain.

\section{Strengths and limitations}

In this prospective cohort study with long follow-up, four repeated surveys collected data on chronic pain using identical questions among a relatively large sample. The response rates to the follow-up surveys were high (78-83\%). Information on a large set of the potential determinants of pain was available and we could control the observed associations for socioeconomic factors, workplace physical and psychosocial factors, and other lifestyle factors. The current study, however, had some limitations. The study had low statistical power to determine the role of lifestyle factors in chronic pain among men. Data on body weight and height, and leisure-time physical activity were based on self-reports. Self-report measures of physical activity may both over- and under-report physical activity [36]. Women may 
underreport their weight and men may over-report their height [37]. We may have therefore underestimated the association between body mass index and chronic pain in both men and women. In all time points, we have collected data on pain in various body locations, such as pain in neck or shoulders, low back, upper limbs, and lower limbs. However, we did not report the associations of body mass index and leisure-time physical activity with pain in different body locations.

\section{Conclusions}

Obesity not only increases the risk of developing chronic pain, but also increases its persistence rate. On the other hand, leisure-time physical activity protects against the development of chronic pain, particularly among individuals who are overweight or obese.

\section{Figure legend}

Figure 1: Flow chart of the study population, Helsinki Health Study

\section{References}

1. Fayaz A, Croft P, Langford RM, Donaldson LJ, Jones GT. Prevalence of chronic pain in the UK: a systematic review and meta-analysis of population studies. BMJ Open. 2016;6:e010364.

2. Shupler MS, Kramer JK, Cragg JJ, Jutzeler CR, Whitehurst DGT. Pan-Canadian Estimates of Chronic Pain Prevalence From 2000 to 2014: A Repeated Cross-Sectional Survey Analysis. J Pain. 2018. 
3. Saxena AK, Jain PN, Bhatnagar S. The Prevalence of Chronic Pain among Adults in India. Indian J Palliat Care. 2018;24:472-77.

4. Dahlhamer J, Lucas J, Zelaya C, Nahin R, Mackey S, DeBar L, et al. Prevalence of Chronic Pain and High-Impact Chronic Pain Among Adults - United States, 2016. MMWR Morb Mortal Wkly Rep. 2018;67:1001-06.

5. Landmark T, Romundstad P, Dale O, Borchgrevink PC, Vatten L, Kaasa S. Chronic pain: One year prevalence and associated characteristics (the HUNT pain study). Scand J Pain. 2013;4:182-87.

6. Tsang A, Von Korff M, Lee S, Alonso J, Karam E, Angermeyer MC, et al. Common chronic pain conditions in developed and developing countries: gender and age differences and comorbidity with depression-anxiety disorders. J Pain. 2008;9:883-91.

7. Mäntyselkä P, Kumpusalo E, Ahonen R, Kumpusalo A, Kauhanen J, Viinamäki H, et al. Pain as a reason to visit the doctor: a study in Finnish primary health care. Pain. 2001;89:175-80.

8. Smith BH, Elliott AM, Chambers WA, Smith WC, Hannaford PC, Penny K. The impact of chronic pain in the community. Fam Pract. 2001;18:292-9.

9. Kawai K, Kawai AT, Wollan P, Yawn BP. Adverse impacts of chronic pain on healthrelated quality of life, work productivity, depression and anxiety in a community-based study. Fam Pract. 2017;34:656-61.

10. McCarthy LH, Bigal ME, Katz M, Derby C, Lipton RB. Chronic pain and obesity in elderly people: results from the Einstein aging study. J Am Geriatr Soc. 2009;57:115-9.

11. Li J, Chen J, Qin Q, Zhao D, Dong B, Ren Q, et al. Chronic pain and its association with obesity among older adults in China. Arch Gerontol Geriatr. 2018;76:12-18.

12. Yamada K, Kubota Y, Iso H, Oka H, Katsuhira J, Matsudaira K. Association of body mass index with chronic pain prevalence: a large population-based cross-sectional study in Japan. J Anesth. 2018;32:360-67. 
13. Dong HJ, Larsson B, Levin LA, Bernfort L, Gerdle B. Is excess weight a burden for older adults who suffer chronic pain? BMC geriatrics. 2018;18:270.

14. Ray L, Lipton RB, Zimmerman ME, Katz MJ, Derby CA. Mechanisms of association between obesity and chronic pain in the elderly. Pain. 2011;152:53-9.

15. Okifuji A, Hare BD. The association between chronic pain and obesity. J Pain Res. 2015;8:399-408.

16. Geneen LJ, Moore RA, Clarke C, Martin D, Colvin LA, Smith BH. Physical activity and exercise for chronic pain in adults: an overview of Cochrane Reviews. Cochrane Database Syst Rev. 2017;4:CD011279.

17. Shiri R, Falah-Hassani K. Does leisure time physical activity protect against low back pain? Systematic review and meta-analysis of 36 prospective cohort studies. Br J Sports Med. 2017;51:1410-18.

18. Nilsen TI, Holtermann A, Mork PJ. Physical exercise, body mass index, and risk of chronic pain in the low back and neck/shoulders: longitudinal data from the Nord-Trondelag Health Study. Am J Epidemiol. 2011;174:267-73.

19. Lahelma E, Aittomäki A, Laaksonen M, Lallukka T, Martikainen P, Piha K, et al. Cohort profile: the Helsinki Health Study. Int J Epidemiol. 2013;42:722-30.

20. Lallukka T, Lahti J, Lahelma E, Rahkonen O. The contribution of smoking to mortality during working age at different levels of leisure-time physical activity. EurJ Public Health. 2016;26:826-30.

21. Ainsworth BE, Haskell WL, Herrmann SD, Meckes N, Bassett DR, Jr., Tudor-Locke C, et al. 2011 Compendium of Physical Activities: a second update of codes and MET values. Med Sci Sports Exerc. 2011;43:1575-81.

22. Kouvonen A, Mänty M, Lallukka T, Lahelma E, Rahkonen O. Changes in psychosocial and physical working conditions and common mental disorders. Eur J Public Health. 2016. 
23. Hanley JA, Negassa A, Edwardes MD, Forrester JE. Statistical analysis of correlated data using generalized estimating equations: an orientation. AmJ Epidemiol. 2003;157:364-75.

24. Arranz LI, Rafecas M, Alegre C. Effects of obesity on function and quality of life in chronic pain conditions. Curr Rheumatol Rep. 2014;16:390.

25. Pietiläinen KH, Kaprio J, Borg P, Plasqui G, Yki-Jarvinen H, Kujala UM, et al. Physical inactivity and obesity: a vicious circle. Obesity (Silver Spring). 2008;16:409-14.

26. Stoner AM, Jastrowski Mano KE, Weisman SJ, Hainsworth KR. Obesity impedes functional improvement in youth with chronic pain: An initial investigation. Eur J Pain. 2017;21:1495-504.

27. Shiri R, Solovieva S, Husgafvel-Pursiainen K, Telama R, Yang X, Viikari J, et al. The role of obesity and physical activity in non-specific and radiating low back pain: the Young Finns study. Semin Arthritis Rheum. 2013;42:640-50.

28. Heuch I, Hagen K, Nygaard O, Zwart JA. The impact of body mass index on the prevalence of low back pain: the HUNT study. Spine. 2010;35:764-8.

29. Shiri R, Solovieva S, Husgafvel-Pursiainen K, Taimela S, Saarikoski LA, Huupponen R, et al. The association between obesity and the prevalence of low back pain in young adults: the Cardiovascular Risk in Young Finns Study. Am J Epidemiol. 2008;167:1110-9.

30. Zdziarski LA, Wasser JG, Vincent HK. Chronic pain management in the obese patient: a focused review of key challenges and potential exercise solutions. J Pain Res. 2015;8:6377.

31. Paley C, Johnson MI. Chronic pain in the obese population: is exercise the key? Pain Manag. 2016;6:121-3.

32. Paley CA, Johnson MI. Physical Activity to Reduce Systemic Inflammation Associated With Chronic Pain and Obesity: A Narrative Review. Clin Pain. 2016;32:365-70. 
33. Wright LJ, Schur E, Noonan C, Ahumada S, Buchwald D, Afari N. Chronic pain, overweight, and obesity: findings from a community-based twin registry. J Pain. 2010;11:628-35.

34. Sullivan AB, Scheman J, Venesy D, Davin S. The role of exercise and types of exercise in the rehabilitation of chronic pain: specific or nonspecific benefits. Curr Pain Headache Rep. 2012;16:153-61.

35. Sitthipornvorakul E, Klinsophon T, Sihawong R, Janwantanakul P. The effects of walking intervention in patients with chronic low back pain: A meta-analysis of randomized controlled trials. Musculoskelet Sci Pract. 2018;34:38-46.

36. Prince SA, Adamo KB, Hamel ME, Hardt J, Connor Gorber S, Tremblay M. A comparison of direct versus self-report measures for assessing physical activity in adults: a systematic review. Int J Behav Nutr Phys Act. 2008;5:56.

37. Ng M, Fleming T, Robinson M, Thomson B, Graetz N, Margono C, et al. Global, regional, and national prevalence of overweight and obesity in children and adults during 1980-2013: a systematic analysis for the Global Burden of Disease Study 2013. Lancet. 2014;384:76681. 


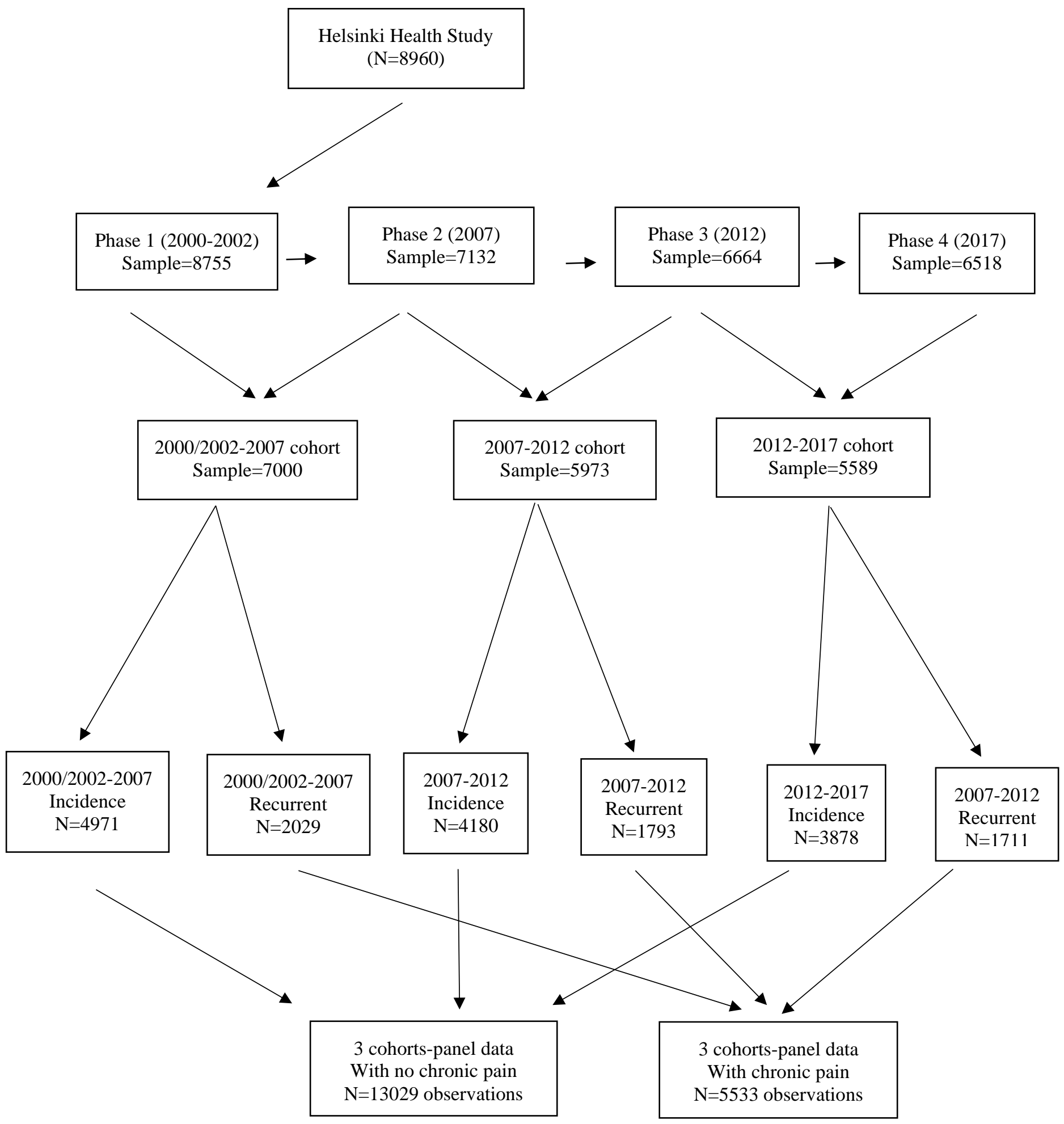


Table 1. Baseline characteristics of the study population, proportions (\%).

\begin{tabular}{lcc}
\hline Characteristic & $\begin{array}{c}\text { Sample without chronic } \\
\text { pain at baseline } \\
(\mathrm{N}=13029 \text { observations) }\end{array}$ & $\begin{array}{c}\text { Sample with chronic } \\
\text { pain at baseline } \\
\text { (N=5533 observations) }\end{array}$ \\
\hline Age in 2000/2002 & 20.5 & 15.1 \\
40 & 21.3 & 19.5 \\
45 & 21.1 & 24.2 \\
50 & 25.2 & 27.9 \\
55 & 11.9 & 13.3 \\
60 & 80.3 & 85.7 \\
Female & & \\
Body mass index & 34.7 & 37.8 \\
Overweight & 14.8 & 21.9 \\
Obese & & \\
Smoking & 26.8 & 28.7 \\
Past & 17.9 & 18.6 \\
Current & & \\
Leisure-time physical activity (MET) & 38.5 & 42.2 \\
Moderate & 40.0 & 29.7 \\
Vigorous & & \\
Physical workload factors & 44.0 & 64.3 \\
Awkward postures & 35.9 & 55.6 \\
Rotation of the back & 33.7 & 54.8 \\
Repetitive movements & 8.3 & 20.7 \\
Heavy physical effort or & & 30.3 \\
lifting/carrying heavy loads & 15.9 & 40.4 \\
Prolonged standing & 26.4 & 5.7 \\
Prolonged sitting & 4.2 & \\
Exposure to vibration & & \\
\hline
\end{tabular}


Table 2: The associations of body mass index and leisure-time physical activity with incident and persistent chronic pain

\begin{tabular}{|c|c|c|c|c|c|c|c|c|c|c|c|c|}
\hline \multirow[t]{2}{*}{ Characteristic } & \multicolumn{4}{|c|}{ Men } & \multicolumn{4}{|c|}{ Women } & \multicolumn{4}{|c|}{ Both genders } \\
\hline & $\mathrm{N}$ & Cases & $\mathrm{OR} *$ & $95 \% \mathrm{CI}$ & $\mathrm{N}$ & Cases & $\mathrm{OR} *$ & $95 \% \mathrm{CI}$ & $\mathrm{N}$ & Cases & $\mathrm{OR} *$ & $95 \% \mathrm{CI}$ \\
\hline \multicolumn{13}{|l|}{ Incident pain } \\
\hline Underweight & 4 & 1 & - & - & 106 & 22 & 1.17 & $0.72-1.91$ & 110 & 23 & 1.19 & $0.74-1.91$ \\
\hline Normal & 1021 & 151 & 1 & & 5376 & 998 & 1 & & 6397 & 1149 & 1 & \\
\hline Overweight & 1138 & 184 & 1.04 & $0.81-1.33$ & 3337 & 752 & 1.21 & $1.08-1.36$ & 4475 & 936 & 1.18 & $1.06-1.31$ \\
\hline Obese & 377 & 82 & 1.47 & $1.06-2.04$ & 1530 & 448 & 1.68 & $1.46-1.94$ & 1907 & 530 & 1.65 & $1.45-1.88$ \\
\hline \multicolumn{13}{|c|}{$\begin{array}{l}\text { Leisure-time } \\
\text { physical activity }\end{array}$} \\
\hline Low & 577 & 105 & 1 & & 2186 & 529 & 1 & & 2763 & 634 & 1 & \\
\hline Moderate & 711 & 119 & 0.97 & $0.72-1.30$ & 4239 & 947 & 0.96 & 0.84-1.09 & 4950 & 1066 & 0.96 & $0.86-1.08$ \\
\hline Vigorous & 1229 & 189 & 0.90 & $0.67-1.19$ & 3920 & 739 & 0.84 & $0.73-0.96$ & 5149 & 928 & 0.85 & $0.75-0.96$ \\
\hline \multicolumn{13}{|c|}{ Persistent pain } \\
\hline \multicolumn{13}{|c|}{$\begin{array}{l}\text { Leisure-time } \\
\text { physical activity }\end{array}$} \\
\hline Low & 238 & 131 & 1 & & 1304 & 740 & 1 & & 1542 & 871 & 1 & \\
\hline Moderate & 237 & 110 & 0.74 & $0.52-1.05$ & 2068 & 1191 & 1.08 & $0.93-1.24$ & 2305 & 1301 & 1.02 & $0.89-1.16$ \\
\hline Vigorous & 299 & 135 & 0.73 & $0.51-1.05$ & 1323 & 702 & 1.02 & $0.86-1.20$ & 1622 & 837 & 0.97 & $0.83-1.12$ \\
\hline
\end{tabular}

* Adjusted for age, gender (both genders combined), education, smoking, body mass index (for leisure-time physical activity) and leisure-time physical activity (for body mass index)

OR, odds ratio; N, number of observations; $\mathrm{CI}$, confidence interval 
Table 3: The associations of body mass index and leisure-time physical activity with incident and persistent chronic pain among working population

\begin{tabular}{|c|c|c|c|c|c|c|}
\hline \multirow[t]{2}{*}{ Characteristic } & \multicolumn{2}{|c|}{ Men } & \multicolumn{2}{|c|}{ Women } & \multicolumn{2}{|c|}{ Both genders } \\
\hline & $\mathrm{OR}^{*}$ & $95 \% \mathrm{CI}$ & $\mathrm{OR}^{*}$ & $95 \% \mathrm{CI}$ & $\mathrm{OR}^{*}$ & $95 \% \mathrm{CI}$ \\
\hline \multicolumn{7}{|c|}{ Incident pain } \\
\hline \multicolumn{7}{|c|}{ Body mass index } \\
\hline Underweight & - & - & 1.18 & $0.68-2.05$ & 1.19 & $0.70-2.04$ \\
\hline Normal & 1 & & 1 & & 1 & \\
\hline Overweight & 0.96 & $0.72-1.28$ & 1.16 & $1.02-1.32$ & 1.13 & $1.00-1.27$ \\
\hline Obese & 1.38 & $0.93-2.04$ & 1.56 & $1.32-1.84$ & 1.54 & $1.32-1.79$ \\
\hline \multicolumn{7}{|c|}{$\begin{array}{l}\text { Leisure-time } \\
\text { physical activity }\end{array}$} \\
\hline Low & 1 & & 1 & & 1 & \\
\hline Moderate & 1.04 & $0.72-1.51$ & 1.08 & $0.93-1.25$ & 1.07 & $0.93-1.23$ \\
\hline Vigorous & 0.92 & $0.65-1.28$ & 0.99 & $0.85-1.16$ & 0.98 & $0.85-1.13$ \\
\hline \multicolumn{7}{|c|}{ Persistent pain } \\
\hline Body mass ind & & & & & & \\
\hline Underweight & - & - & 0.90 & $0.41-1.99$ & 0.85 & $0.39-1.84$ \\
\hline Normal & 1 & & 1 & & 1 & \\
\hline Overweight & 0.91 & $0.60-1.36$ & 1.11 & $0.95-1.31$ & 1.08 & $0.93-1.25$ \\
\hline Obese & 1.64 & $0.97-2.78$ & 1.26 & $1.02-1.54$ & 1.30 & $1.08-1.58$ \\
\hline \multicolumn{7}{|c|}{$\begin{array}{l}\text { Leisure-time } \\
\text { physical activity }\end{array}$} \\
\hline Low & 1 & & 1 & & 1 & \\
\hline Moderate & 0.61 & $0.39-0.96$ & 1.11 & $0.93-1.32$ & 1.03 & $0.87-1.21$ \\
\hline Vigorous & 0.74 & $0.48-1.13$ & 1.09 & $0.90-1.32$ & 1.03 & $0.86-1.23$ \\
\hline
\end{tabular}

* Adjusted for age, gender (both genders combined), education, marital status, household income, smoking, body mass index (for leisure-time physical activity), leisure-time physical activity (for body mass index), back rotation, back repetitive, heavy physical work or lifting/carrying heavy loads, awkward posture, prolonged standing, prolonged sitting, job demands and job control

OR, odds ratio; $\mathrm{N}$, number of observations; $\mathrm{CI}$, confidence interval 
Table 4: The joint effects of body mass index and leisure-time physical activity on incident and persistent chronic pain

\begin{tabular}{|c|c|c|c|c|c|c|c|c|c|c|c|c|c|}
\hline \multirow[t]{2}{*}{ Body mass index } & \multirow{2}{*}{$\begin{array}{l}\text { Leisure-time } \\
\text { physical activity }\end{array}$} & \multicolumn{4}{|c|}{ Men } & \multicolumn{4}{|c|}{ Women } & \multicolumn{4}{|c|}{ Both genders } \\
\hline & & $\mathrm{N}$ & Cases & OR* & $95 \% \mathrm{CI}$ & $\mathrm{N}$ & Cases & $\mathrm{OR} *$ & $95 \% \mathrm{CI}$ & $\mathrm{N}$ & Cases & $\mathrm{OR}^{*}$ & $95 \% \mathrm{CI}$ \\
\hline \multicolumn{14}{|c|}{ Incident pain } \\
\hline Normal & Low & 167 & 21 & 1 & & 803 & 145 & 1 & & 970 & 166 & 1 & \\
\hline Overweight or obese & Low & 407 & 83 & 1.79 & $1.06-3.04$ & 1354 & 380 & 1.71 & $1.37-2.13$ & 1761 & 463 & 1.71 & $1.40-2.09$ \\
\hline Normal & Moderate & 235 & 39 & 1.51 & $0.84-2.69$ & 2040 & 404 & 1.13 & $0.91-1.39$ & 2275 & 443 & 1.16 & $0.95-1.42$ \\
\hline Overweight or obese & Moderate & 470 & 80 & 1.43 & $0.84-2.43$ & 2153 & 527 & 1.45 & $1.18-1.78$ & 2623 & 607 & 1.44 & $1.19-1.75$ \\
\hline Normal & Vigorous & 604 & 90 & 1.26 & $0.75-2.12$ & 2582 & 457 & 0.99 & $0.80-1.22$ & 3186 & 547 & 1.03 & $0.85-1.25$ \\
\hline Overweight or obese & Vigorous & 613 & 96 & 1.29 & $0.77-2.17$ & 1301 & 274 & 1.19 & $0.95-1.50$ & 1914 & 370 & 1.20 & $0.97-1.47$ \\
\hline \multicolumn{14}{|c|}{ Persistent pain } \\
\hline Normal & Low & 62 & 37 & 1 & & 370 & 186 & 1 & & 432 & 223 & 1 & \\
\hline Overweight or obese & Low & 170 & 91 & 0.81 & $0.45-1.46$ & 917 & 546 & 1.34 & $1.05-1.73$ & 1087 & 637 & 1.25 & $0.99-1.58$ \\
\hline Normal & Moderate & 78 & 35 & 0.56 & $0.30-1.04$ & 792 & 419 & 1.10 & $0.85-1.41$ & 870 & 454 & 1.00 & $0.79-1.27$ \\
\hline Overweight or obese & Moderate & 158 & 75 & 0.66 & $0.36-1.20$ & 1256 & 758 & 1.38 & $1.08-1.75$ & 1414 & 833 & 1.24 & $0.99-1.55$ \\
\hline Normal & Vigorous & 129 & 53 & 0.55 & $0.30-1.02$ & 748 & 376 & 1.01 & $0.78-1.31$ & 877 & 429 & 0.93 & $0.73-1.17$ \\
\hline Overweight or obese & Vigorous & 165 & 81 & 0.64 & $0.35-1.16$ & 559 & 318 & 1.31 & $1.00-1.72$ & 724 & 399 & 1.18 & $0.92-1.51$ \\
\hline
\end{tabular}

* Adjusted for age, gender (both genders combined), education and smoking

$\mathrm{OR}$, odds ratio; $\mathrm{N}$, number of observations; $\mathrm{CI}$, confidence interval 